\title{
Adjusting Productivity for Pollution in Selected Asian Economies
}




\section{OECD GREEN GROWTH PAPERS}

The OECD Green Growth Strategy, launched in May 2011, provides concrete recommendations and measurement tools to support countries' efforts to achieve economic growth and development, while at the same time ensuring that natural assets continue to provide the ecosystem services on which our well-being relies. The strategy proposes a flexible policy framework that can be tailored to different country circumstances and stages of development.

OECD Green Growth Papers should not be reported as representing the official views of the OECD or of its member countries. The opinions expressed and arguments employed are those of the author(s).

OECD Green Growth Papers aim to describe preliminary results or research in progress by the author(s) and are published to stimulate discussion on specific topics and obtain feedback from interested audiences. They complement the OECD Green Growth Studies series, which aims to provide in-depth reviews of the green growth issues faced by different sectors.

This paper has been authorised for publication by Simon Upton, Director, Environment Directorate.

Comments on Green Growth Papers are welcomed, and may be sent to:

OECD Green Growth Unit, 2, rue André Pascal, 75775 PARIS CEDEX 16, France

or by email to greengrowth@oecd.org.

OECD Green Growth Papers are published on

www.oecd.org/greengrowth

Please cite this paper as

Dang, T. and A. Mourougane (2014), "Adjusting Productivity for Pollution in Selected Asian Economies", OECD Green Growth Papers, 2014-01, OECD Publishing, Paris.

(c) OECD (2014)

You can copy, download or print OECD content for your own use, and you can include excerpts from OECD publications, databases and multimedia products in your own documents, presentations, blogs, websites and teaching materials, provided that suitable acknowledgment of OECD as source and copyright owner is given.

All requests for commercial use and translation rights should be submitted to rights@oecd.org 


\section{FOREWORD}

The objective of this paper is to estimate the effect on multifactor productivity (MFP) of air pollution in 7 ASEAN economies (Cambodia, Indonesia, Lao PDR, Malaysia, Philippines, Thailand and Vietnam) and China. For this purpose, standard measures of MFP are corrected for the impact of pollution applying the framework developed by Brandt et al. (2014), and valuing pollution through country-specific time-varying shadow price estimates for $\mathrm{CO}_{2}, \mathrm{SO}_{\mathrm{x}}, \mathrm{NO}_{\mathrm{x}}$ and $\mathrm{PM}_{10}$, derived from an output distance function approach. Shadow prices of pollutants, the opportunity cost of abating pollution in the form of reduced output, are found to vary widely across economies, depending on national environmental regulations, the use of inefficient abatement technologies, and the structure of the economy. In all countries but Cambodia, shadow prices of the various pollutants experience a downward trend since the Asian crisis, suggesting that ASEAN countries and China have strengthened their regulatory framework and encouraged the adoption of clean technologies. Accounting for pollution leads to very different adjustments to standard MFP measures across countries. In most countries the adjustment is positive, suggesting that standard MFP measures have tended to underestimate the true measure. Such correction would be above 2 percentage points in Lao PDR and the Philippines. It is estimated to be around 1 percentage point in China, Indonesia and Thailand and about half that size in Malaysia. It would be negative in Cambodia and nil in Vietnam.

This paper was authored by Thai-Thanh Dang and Annabelle Mourougane, consultant and senior economist respectively in the OECD Green Growth Unit headed by Nathalie Girouard.

The authors would like thank Nicola Brandt, Jan Corfee-Morlot, Vincent Koen, Justine Garrett, Mauro Pisu, Ziga Zarnic and Vera Zipperer for their constructive comments. Britta Labuhn contributed to an earlier version of this work. This paper should not be reported as representing the official views of the OECD or of its member countries. The opinions expressed and arguments employed are those of the author(s).

The financial support of Korea International Cooperation Agency is gratefully acknowledged. 


\section{TABLE OF CONTENTS}

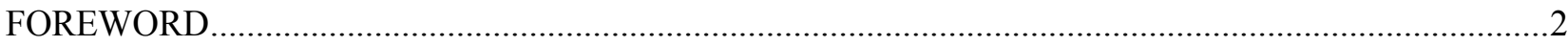

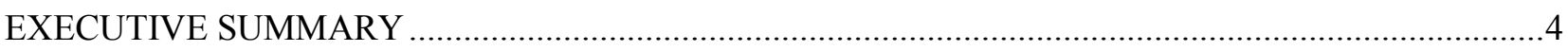

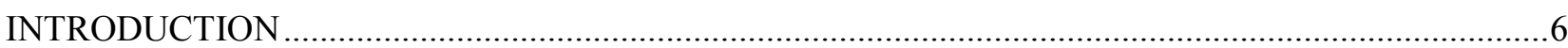

1. ECONOMIC GROWTH AND RAPID URBANISATION HAVE BEEN ACCOMPANIED BY

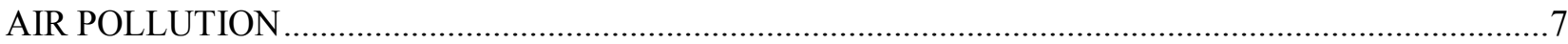

2. COMPUTING PRODUCTIVITY IN ASEAN ECONOMIES AND CHINA ….............................10

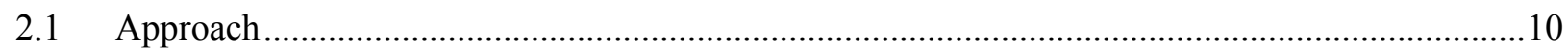

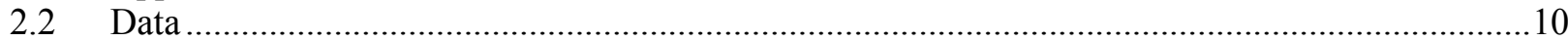

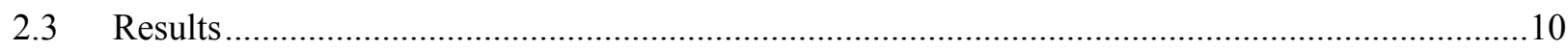

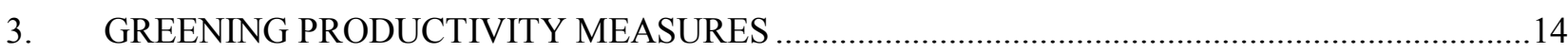

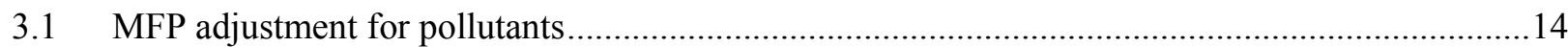

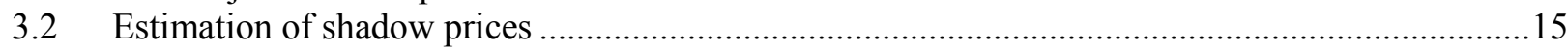

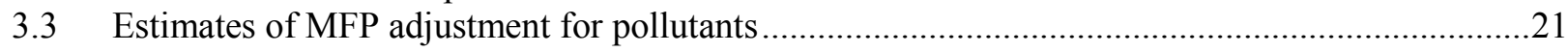

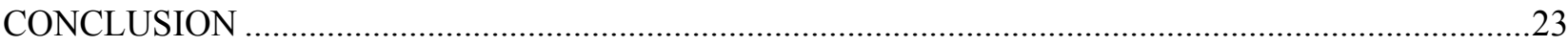

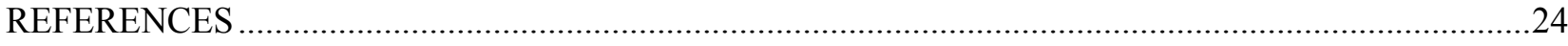

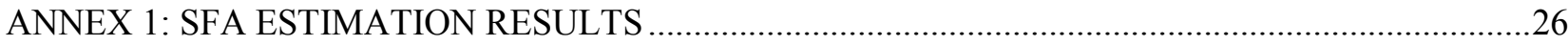

Tables

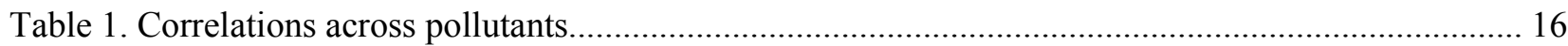

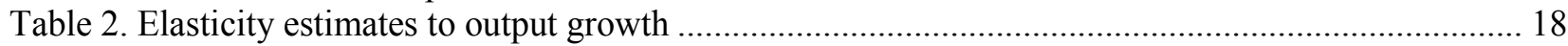

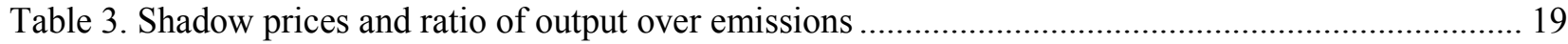

Table 4. MFP growth adjustment for pollution ................................................................................... 22

\section{Figures}

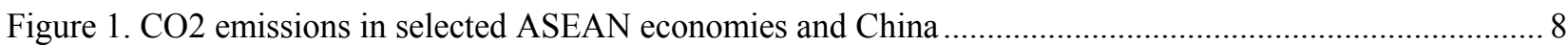

Figure 2. Local air pollution in selected ASEAN economies and China...................................................... 8

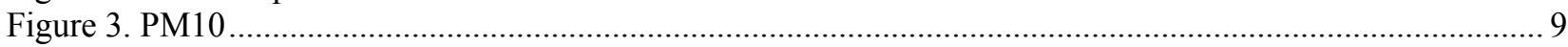

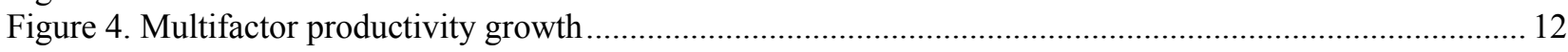

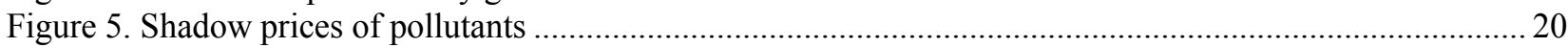

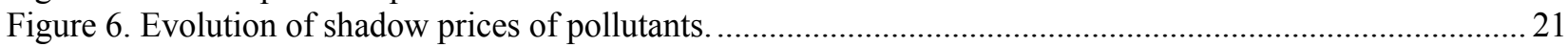




\section{EXECUTIVE SUMMARY}

Multifactor productivity (MFP) is increasingly used in economic policy, not least to compute potential output. Most measures are based on a standard production function combining labour and capital, but do not incorporate the negative by-products of the production process such as air pollution that could have deleterious effect on health and productivity in the medium to long term (see for instance OECD (2014)). The failure to account for the costs of environmental damages and the benefits associated with emission reduction impart a bias to standard measures of MFP. Ignoring these dimensions can give a misleading idea of growth prospects over the medium to long term.

The objective of this paper is to estimate the effect on MFP of air pollution in 7 ASEAN economies (Cambodia, Indonesia, Lao PDR, Malaysia, Philippines, Thailand and Vietnam) and China. For this purpose, measures of MFP are computed using the OECD Productivity database approach ((http://www.oecd.org/std/productivity-stats/). These estimates are then corrected for the impact of pollution by applying the framework developed by Brandt et al. (2014), and valuing pollution through country-specific timevarying shadow price estimates derived from the estimation of an output distance function for four gas emissions $\mathrm{CO}_{2}, \mathrm{SO}_{2}, \mathrm{NO}_{\mathrm{x}}$ and $\mathrm{PM}_{10}$. This approach is described in details in Dang and Mourougane (2014).

Empirical results point to the following conclusions:

- ASEAN economies were hit hard by the 1997-98 Asian crisis with a marked fall in standard measures of MFP growth. The shock was severe but short-lived and productivity growth recovered rapidly to reach some $3 \%$ per year during the 2000s on average in emerging ASEAN economies (Indonesia, Malaysia, Philippines and Thailand). Developing ASEAN countries (Cambodia, Lao PDR and Vietnam) experienced stronger productivity growth during that period, though the latter estimation should be interpreted with great care given the paucity of data for these countries.

- Shadow prices of pollutants, the opportunity cost of abating pollution in the form of reduced output, are found to vary widely across economies, depending on national environmental regulations, the use of inefficient abatement technologies, and the structure of the economy. Low shadow prices (in absolute terms) would signal less stringent regulations or weak compliance towards existing regulation.

- $\mathrm{CO}_{2}$ shadow prices are estimated to be the lowest (in absolute terms) in China and the highest in Cambodia and the Philippines. Shadow prices for $\mathrm{SO}_{2}$ would be significantly higher than those of $\mathrm{CO}_{2}$ and are estimated to be the lowest China and the highest in Malaysia. Shadow prices for other pollutants (NOx and $\mathrm{PM}_{10}$ ) would be the highest in Malaysia and the lowest in Lao PDR.

- In all countries but Cambodia, shadow prices of the various pollutants experience a downward trend since 1999, suggesting that ASEAN countries and China have strengthened their regulatory framework and encouraged the adoption of clean technologies since the Asian crisis. Such a trend can also be observed in Cambodia but only for the shadow price of $\mathrm{CO}_{2}$. 
- Overall the amplitude of the adjustment for pollution of standard measures of MFP growth appears to be relatively sizeable, though probably still within the margin of errors of such measures. In most countries, activity grew faster than gas emissions leading to a positive adjustment of pollution and suggesting that standard measures of MFP have underestimated the 'true' value of MFP in most countries. Accounting for pollution leads to very different adjustments across countries. Such correction would be above 2 percentage points in Lao PDR and the Philippines, around 1 percentage point in China, Indonesia and Thailand and about half that size in Malaysia. It would be negative in Cambodia and nil in Vietnam.

- The order of magnitude of the adjustment needs to be interpreted with caution. Indeed, only costs to producers of polluting are examined in this framework. Costs to the society as a whole are likely to be much more sizeable. In addition, this analysis accounts for only a limited number of pollutants and relies on a set of data which is likely to capture the real world only imperfectly, as informality is widespread in many Asian countries. 


\section{INTRODUCTION}

Robust economic growth and rapid urbanisation have been accompanied by marked environmental deterioration in ASEAN economies and China. Air pollution has been growing and is now at worrisome levels. Man-made emissions of $\mathrm{CO}_{2}$ have significantly risen though their levels per capita remain relatively low by international standards. $\mathrm{NOx}$ and $\mathrm{SO}_{2}$ emissions have also been growing.

Relying extensively on high-polluting industries can boost output in the short term, but is likely to create negative externalities in the form of air pollution that can have deleterious effect on health and productivity and affect production in the long term. In such a context, the failure to account for the costs of environmental damages and the benefits associated with emission reduction impart a bias to standard measures of multi-factor productivity (MFP).

The objective of this paper is to estimate the effect on MFP of air pollution in 7 ASEAN economies (Cambodia, Indonesia, Lao PDR, Malaysia, Philippines, Thailand and Vietnam) and China. For this purpose, measures of MFP are computed using the OECD Productivity database approach (http://www.oecd.org/std/productivity-stats/). These estimates are then corrected for the impact of pollution by applying the framework developed by Brandt et al. (2014) and valuing pollution through shadow price estimates derived from the estimation of an output distance function. This approach is described in details in Dang and Mourougane (2014).

The paper unfolds as follows. A first section briefly describes developments in air pollution in ASEAN economies and China. A second section details the methodology adopted to compute MFP growth in selected ASEAN economies and China. A third section adjusts MFP growth estimates for the impact of pollution and, for this purpose, derives country-specific and time-varying shadow prices of pollution explicitly. A last section concludes. 


\section{ECONOMIC GROWTH AND RAPID URBANISATION HAVE BEEN ACCOMPANIED BY AIR POLLUTION}

As a consequence of rapid and carbon intensive growth in the region, $\mathrm{CO}_{2}$ emissions have been growing in ASEAN economies at a fast rate, even though they are in volumes still lower than in other regions of the world (Figure 1). Looking forward, the share of ASEAN emissions in global emissions is expected to increase rapidly in the coming years reflecting rapid economic growth and further urbanisation, changing life style and higher demand for energy.

One of the main sources of air pollution is acid rain, stemming from too much sulfur dioxide $\left(\mathrm{SO}_{2}\right)$ in the air. Acid rains lead to environment degradation (especially on forestry and biodiversity) and can also cause sickness. $\mathrm{SO}_{2}$ emissions have been rising rapidly in most ASEAN economies, although in some countries such as Vietnam levels remain relatively low (Figure 2). Another prominent air pollutant in Asia is nitrogen oxides $\left(\mathrm{NO}_{\mathrm{x}}\right)$, for which most ASEAN economies experienced a rapid rise in the last decade.

The level of atmospheric or suspended particulate matters of 10 micrometre diameter (PM10) has risen in most ASEAN countries in the most recent period, and the rise was substantial in China (Figure 3). In the latter country, the critical situation led the government to introduce concentration targets for PM10 (Clean Air Alliance of China, 2013). Within countries, developments in $\mathrm{PM}_{10}$ emissions could hide wide disparities between urban and rural areas. In particular, concentrations in $\mathrm{PM}_{10}$ in urban areas appear to have substantially declined over the years, possibly thanks to mitigating measures implemented by ASEAN governments (Sheng, 2012). 
Figure 1. CO2 emissions in selected ASEAN economies and China

$\mathrm{CO}_{2}$ emissions

Millions tons

$\square 2000 \quad \square 2008$

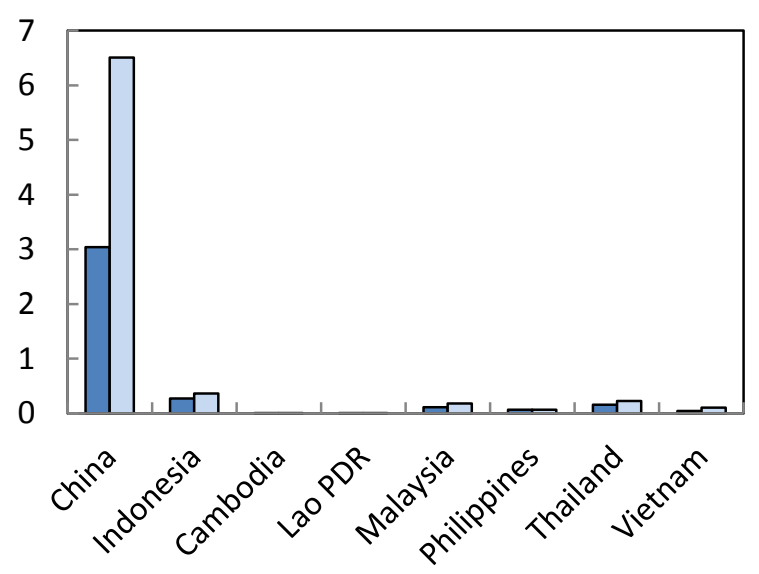

$\mathrm{CO}_{2}$ emissions per GDP

Kilogramme per thousand USD PPP

$\square 2000 \quad \square 2008$

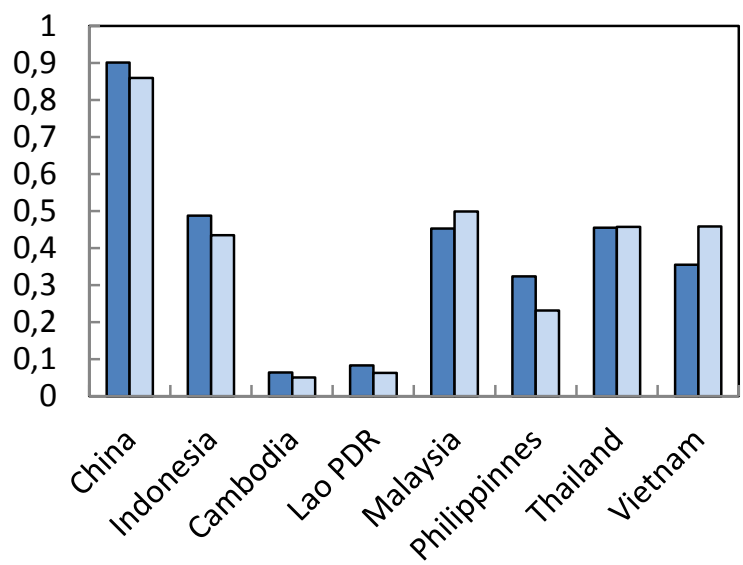

Source: World Bank and IAE.

Figure 2. Local air pollution in selected ASEAN economies and China Thousand tons

NOx emissions

$\square 2000 \quad \square 2008$

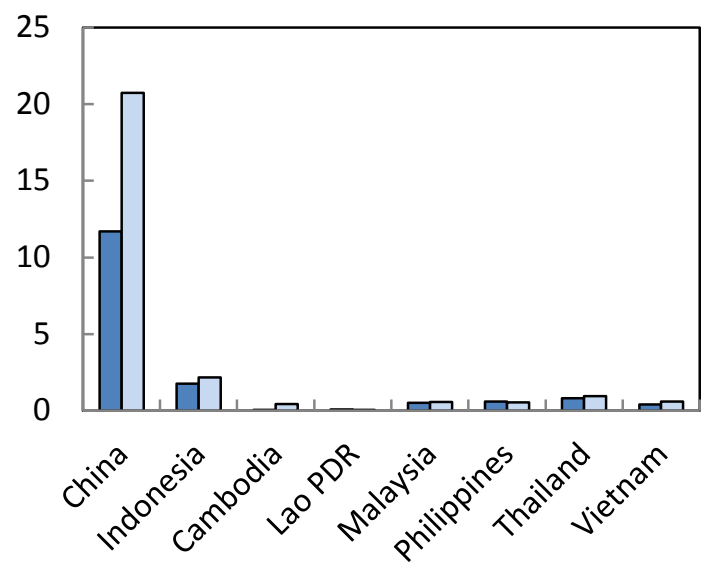

$\mathrm{SO}_{2}$ emissions

$\square 2000 \square 2008$

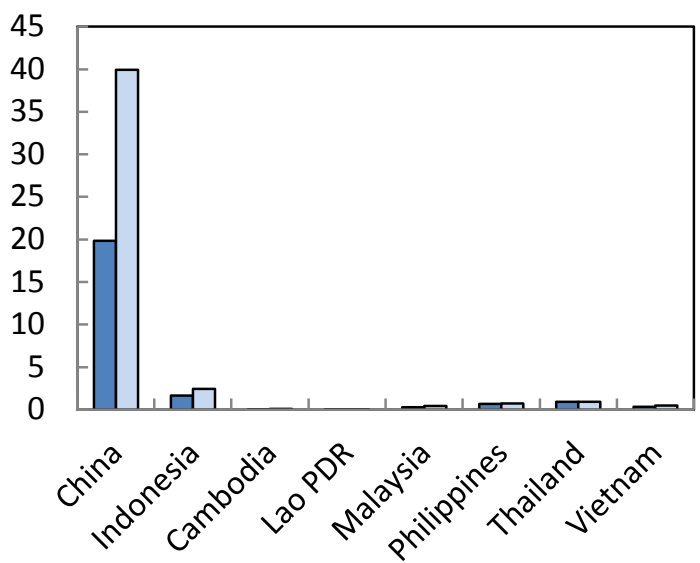

Source: EDGAR. 


\section{Figure 3. $\mathrm{PM}_{10}$}

$\mathrm{PM}_{10}$ concentrations in urban areas Microgrammes per m3

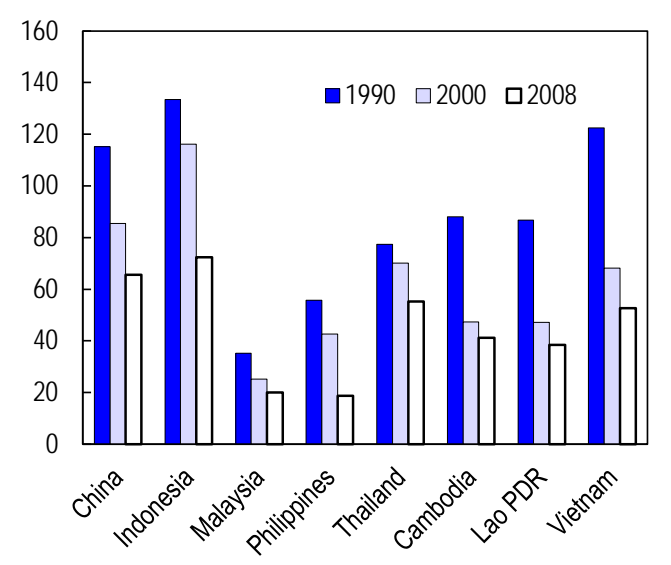

$\mathrm{PM}_{10}$ volumes

Thousand tons

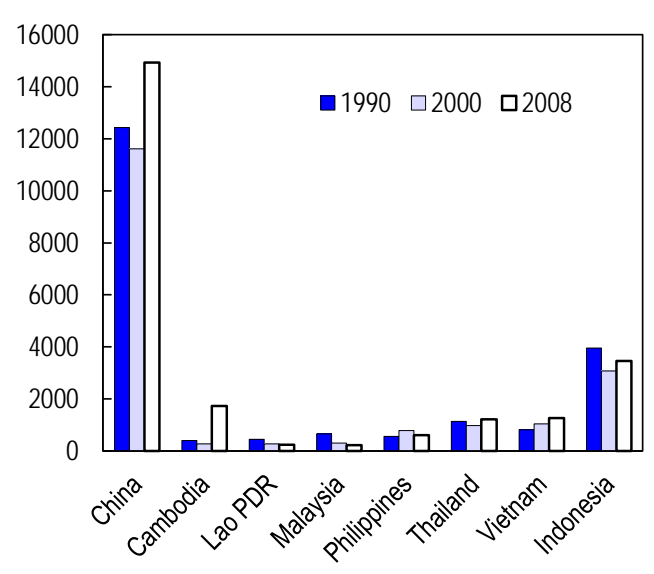

Source: World Bank and EDGAR. 


\section{COMPUTING PRODUCTIVITY IN ASEAN ECONOMIES AND CHINA}

A first step of the analysis is to compute MFP measures which are not readily available for ASEAN economies. Two methods have been used for this purpose: a baseline measure which is consistent with the OECD Productivity methodology and a standard Cobb-Douglas measure, which allows to check the robustness and the plausibility of the baseline estimates.

\section{$2.1 \quad$ Approach}

MFP growth is first derived in a way that is consistent with the OECD productivity database approach. It consists of computing an 'apparent' MFP measure that is the ratio between a volume index of output and a volume index of the observed inputs. Such a measure is a residual and reflects the combined effects of technical change, of unobserved inputs, of non-constant returns to scale and, indirectly, of deviations from perfect competition in product markets (Schreyer, 2010).

The main advantage of this methodology is that it does not assume a predetermined technology and allows having variations across countries. This is important as the group of ASEAN economies is very heterogeneous. The main difficulty of computing such measures is that it requires data on total compensation, which are not available for some ASEAN countries.

To check the plausibility of the resulting estimates, MFP measures derived from a standard Cobb-Douglas production function are also presented. In this approach, MFP growth is computed as a residual from the following equation: $m f p_{t}=y_{t}-(1-\alpha) * k_{t}-\alpha\left(1-u_{t}\right) * l f_{t}$ where $y_{t}$ denotes actual output, $k_{t}$ capital stock, $u_{t}$ is the rate of unemployment and $l f_{t}$ is labour force. Such data are similar to those calculated in the OECD Economic Outlook and described in Beffy et al. (2006).

\section{$2.2 \quad$ Data}

Calculations have been carried out with annual data for the period 1991-2009, except for Cambodia and Vietnam for which data were only available after the Asian crisis. Data for GDP, gross capital formation, labour force and the unemployment rate are taken from the World Bank's WDI database or in some cases, where the sample was restricted, national sources. Capital stocks were constructed using the perpetual inventory method and a fixed depreciation rate of 5\%. A 7\% depreciation rate would lead to very similar results. Missing values in the unemployment rate series were interpolated linearly.

\section{$2.3 \quad$ Results}

Both measures of MFP, the one consistent with the OECD productivity database approach and the one computed with a Cobb-Douglas approach, display a similar pattern (Figure 4). There appears to be some difference in levels for China, and for some countries at some point in time, but those latter differences remains small compared to the traditionally high uncertainties surrounding MFP growth estimates. These results are also comparable with other estimations reported in Park (2010) or data computed by the Asian Productivity Organisation, for all countries but Vietnam. In this country, existing divergences may reflect the lack of official 
and reliable data for compensation which requires estimating it in an ad hoc manner. In what follows, we thus use a Cobb-Douglas measure for Vietnam, which can be computed without compensation data.

According to these calculations, ASEAN economies have been seriously affected by the 1997-98 Asian crisis which resulted in a marked fall in MFP growth. The shock was severe but short-lived and productivity growth recovered rapidly to reach some $3 \%$ per year during the 2000 s on average in emerging ASEAN economies. Developing ASEAN economies experienced stronger productivity growth during that period, though the latter estimation should be interpreted with great care given the paucity of data. All countries but the Philippines have undergone a deceleration in MFP since the mid 2000s. 
Figure 4. Multifactor productivity growth, per cent

China

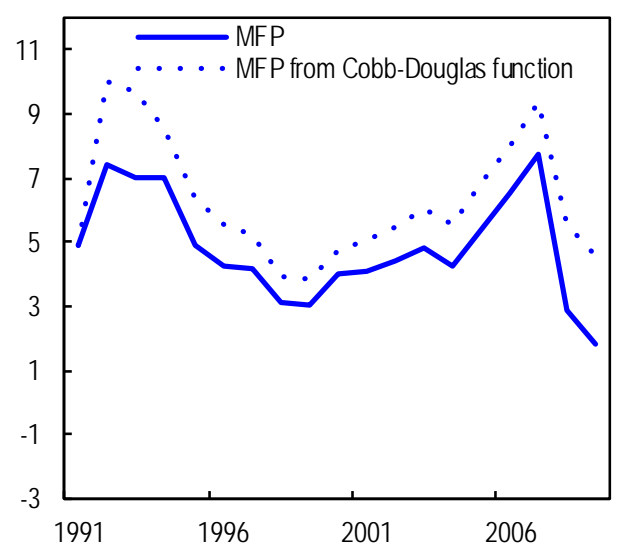

Malaysia

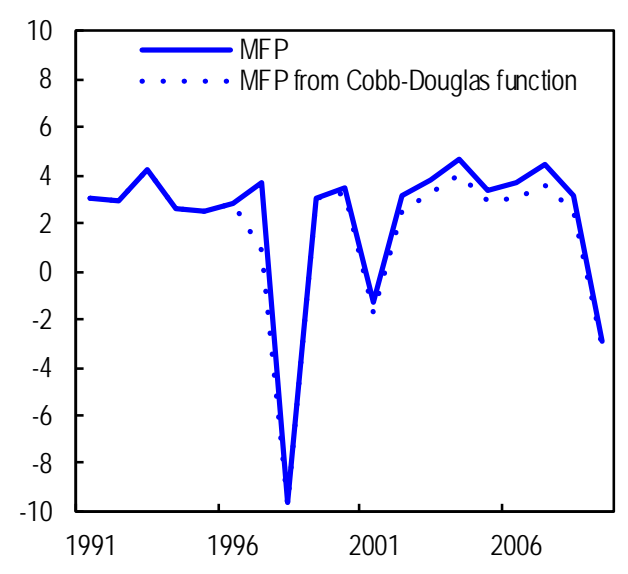

Thailand

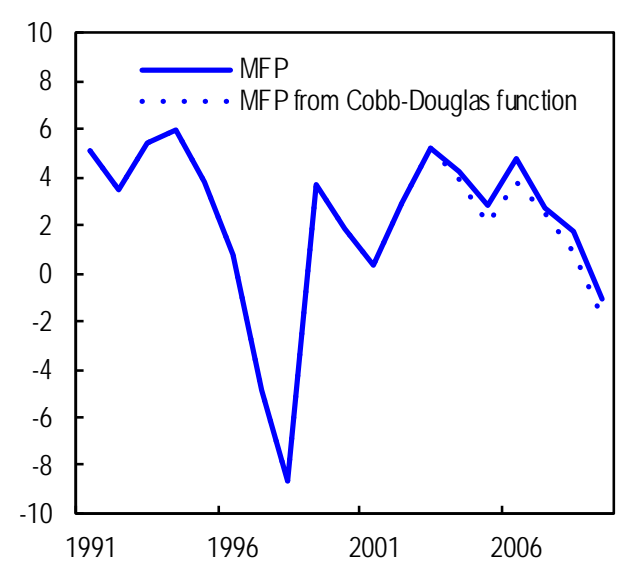

Indonesia

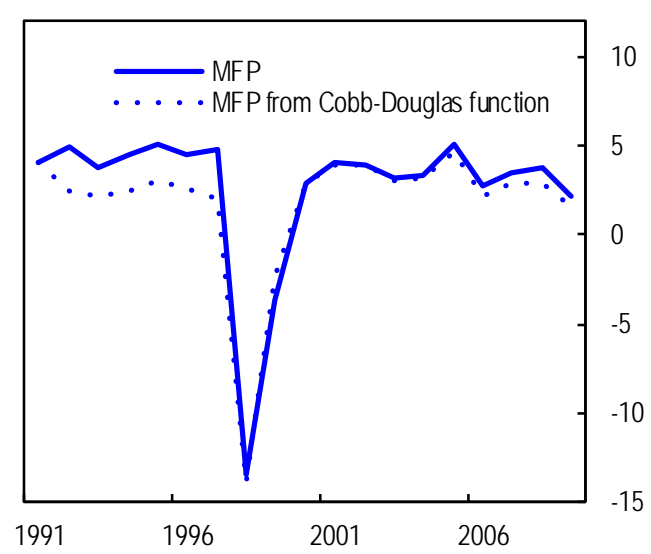

Philippines

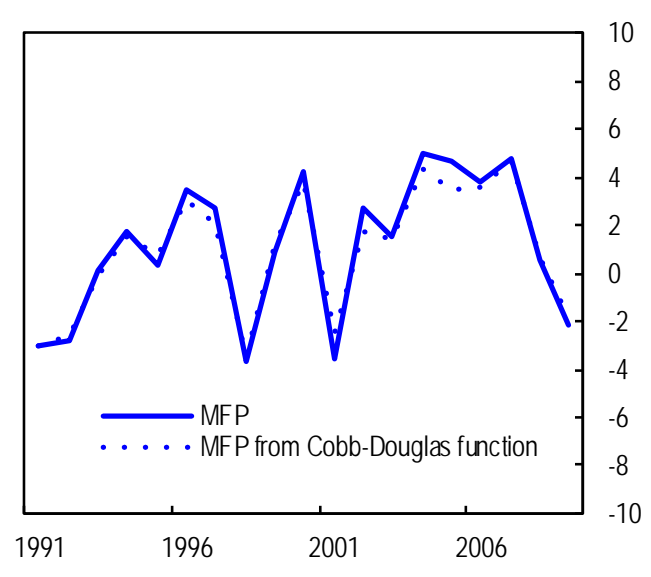

\section{Vietnam}

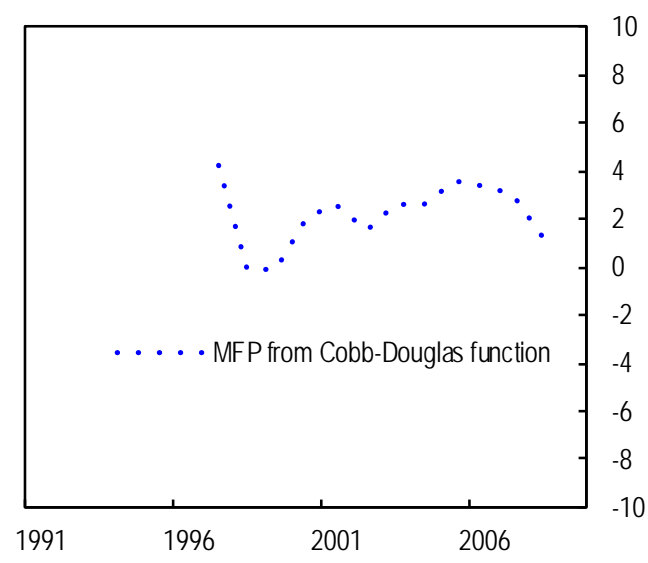


Figure 4. Multifactor productivity growth, per cent (con't)

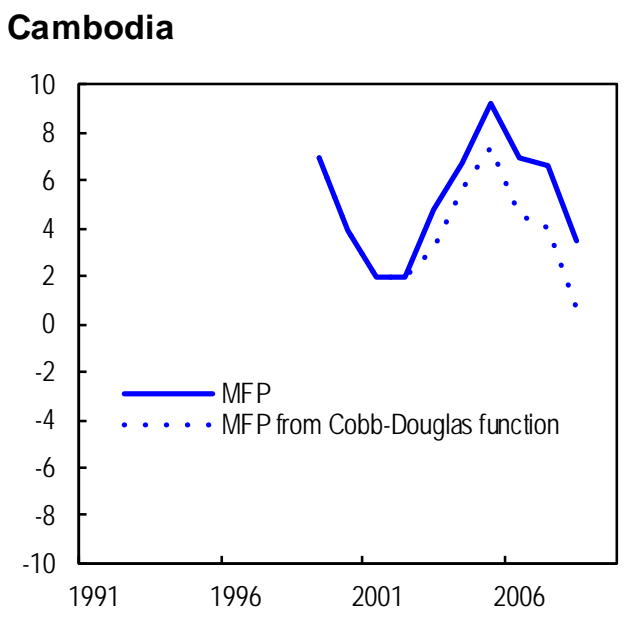

\section{Lao PDR}

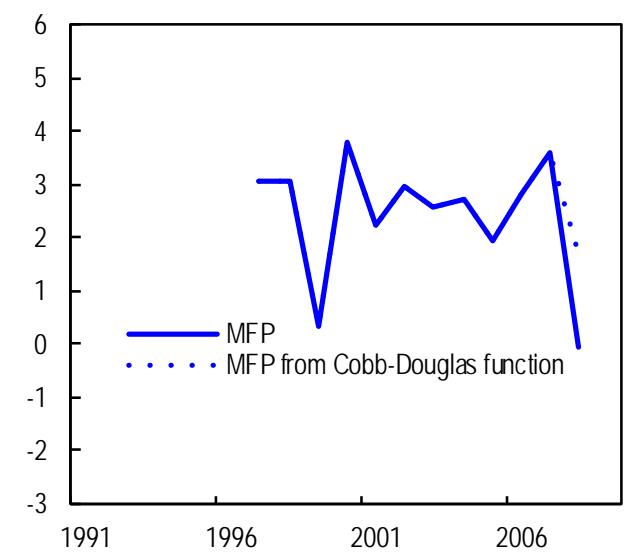

Source: Authors' calculations. 


\section{GREENING PRODUCTIVITY MEASURES}

\subsection{MFP adjustment for pollutants}

This paper relies and expands on the methodology developed by Brandt et al. (2014). It relies on a growth accounting rather an econometrics approach, and on Solow (1957). The framework is based on a standard production function, whereby output $\mathrm{Y}$ is produced using labour and capital input factors. This function is complemented by undesirable outputs, mainly pollution, that are produced jointly with goods and services. More specifically two adjustments are made to the standard production function. First, natural capital inputs (including minerals, oil, gas, coal and forest) are aggregated into a natural resource index and enter the production function as a third input factor. Second, 'undesirable outputs', essentially $\mathrm{CO}_{2}, \mathrm{NO}_{\mathrm{x}}, \mathrm{SO}_{2}$ and $\mathrm{PM} 10$ emissions, are combined with $\mathrm{Y}$ to derive an "effective output" $\mathrm{Q}$.

In formal terms, effective output is defined as $Q\left(W_{t}, Y_{t}\right)=f\left(K_{t}, L_{t}, S_{t}\right)$

where Q denotes effective output, $\mathrm{Y}$ is the output of goods and services, $\mathrm{W}$ are the undesirable or bad outputs, $\mathrm{K}$ capital input, $\mathrm{L}$ labour input and $\mathrm{S}$ the flow of natural resources. $\mathrm{S}$ is an aggregate of different natural resource inputs.

Inputs can be used to increase desirable output $(\mathrm{Y})$ or reduce undesirable output $(\mathrm{W})$. However, reducing pollution is costly and a drastic reduction can hamper economic growth in the short term. Constant returns to scale are assumed, implying that $\mathrm{Q}$ (resp f) is homogenous of degree 1 in $\mathrm{Y}$ and $\mathrm{W}$ (resp. in $\mathrm{K}, \mathrm{L}$ and $\mathrm{S}$ ).

$$
\begin{aligned}
& \frac{d Q}{d Y}>0 \text { and } \frac{d Q}{d W}<0 \\
& \frac{d f}{d K}>0 \text { and } \frac{d f}{d L}>0 \text { and } \frac{d f}{d S}>0 \\
& \frac{d^{2} f}{d K^{2}}<0 \text { and } \frac{d^{2} f}{d L^{2}}<0 \text { and } \frac{d^{2} f}{d S^{2}}<0
\end{aligned}
$$

According to Aiken and Pasurka (2003), there are two advantages of modelling the joint production of desirable and undesirable outputs. First, this does not require information on pollution abatement technologies and their costs. Instead the cost of pollution abatement activities is captured by the reduced production of the desirable output that results from the reallocation of inputs to pollution abatement activities. Second, the synergies in the abatement process of two or more pollutants are automatically handled by the production technology. relation:

Following Brandt et al. (2014), MFP estimates are adjusted for undesirable outputs using the following

$$
m f p_{a d j \_p o l}=m f p-\frac{p_{w} W}{p_{Q Q}}(y-w)
$$

Where mfpadj pol $_{\text {pol }}$ is the growth rate of MFP adjusted for air pollution, $p_{w}$ is the shadow price of pollution, $\mathrm{W}$ the quantity of pollutants, $\mathrm{p}_{\mathrm{Q}}$ the price of effective output, $\mathrm{Q}$ effective output, $\mathrm{y}$ the growth rate of the 
desirable output and $\mathrm{w}$ the growth rate of the quantity of pollution emitted during the production process. The time index $t$ has been omitted. The objective of the next section is to estimate $p_{w}$, the shadow price of pollution, which cannot be observed.

\subsection{Estimation of shadow prices}

\section{Approach}

This paper relies on an output distance function that has been widely used in the economic literature (Färe et al., 1989, 1993, 2005, 2010; Kumar and Rao, 2002; Hu, 2006; Murty et al., 2002). It follows Dang and Mourougane (2014) who show that, using the Shephard duality (1970) between the output distance function and the revenue function, and the homogeneity property of the distance function, the shadow prices of undesirable output can be expressed as

$$
p_{w}=p_{y} \frac{y}{w} e(y, w)
$$

Where $\mathrm{p}_{\mathrm{w}}$ and $\mathrm{p}_{\mathrm{y}}$ are respectively the shadow price of undesirable output and of desirable output, $\mathrm{e}(\mathrm{y}, \mathrm{w})$ is the output-undesirable output elasticity at the frontier of efficiency, or the quantity of good output that must be forgone to reduce the quantity of one per cent of bad output, and $\left(\frac{y}{w}\right)$ the pollutant intensity ratio or the actual output mix, which is a function of the current technology and to some degree the structure of the economy.

Shadow prices are negative as they measure the opportunity cost on the desirable output of reducing the undesirable outputs at the actual mix of output, which may or may not be consistent with the maximum allowable under regulation (Färe et al., 1993). The higher the value of the shadow price, the higher the opportunity cost for achieving additional reduction in the production of undesirable outputs.

High shadow prices point to the weakness of a country's regulations and/or the lack of compliance with regulations. Indeed, the regulatory framework may entice plants to adopt more efficient technologies so as to reduce their emission of pollutants while holding constant their level of desirable output. However, environment regulations are not the only factor at play. Technological improvement may indirectly occur driven by other factors such as the implementation of structural policies or change in the international business environment, leading to cleaner production processes. The structure of the economy will also affect shadow prices' developments.

Using a translog function as a functional form of the output distance function, it can be shown that

$$
e\left(y, w_{r}\right)=\gamma_{r}+\frac{1}{2} \sum_{s=1}^{R}\left(\gamma_{r s}+\gamma_{s r}\right) \ln w_{s}+\sum_{k=1}^{K} \varepsilon_{k r} \ln x_{k}
$$

Where $\mathrm{x}$ is the quantity of input (capital, labour and natural resource).

The parameters $\gamma$ and $\varepsilon$ can be derived from estimating the following equation (4):

$$
\begin{aligned}
-\ln (y)=\alpha_{0} & +\sum_{k=1}^{K} \alpha_{k} \ln x_{k i}+\frac{1}{2} \sum_{k=1}^{K} \sum_{l=1}^{K} \alpha_{k l} \ln x_{k i} \ln x_{l i}+\sum_{r=1}^{R} \gamma_{r} \ln w_{r i}+\frac{1}{2} \sum_{r=1}^{R} \sum_{s=1}^{R} \gamma_{r s} \ln w_{r i} \ln w_{s i} \\
& +\sum_{k=1}^{K} \sum_{r=1}^{R} \varepsilon_{k r} \ln x_{k i} \ln w_{r i}+u_{i}+\omega_{i}
\end{aligned}
$$


$\mathrm{u}_{\mathrm{i}}$ captures time invariant inefficiency, which is assumed to have a half normal distribution and $\omega_{\mathrm{i}}$ is the standard error term following a normal distribution. This differs slightly from the more general methodology set out in Dang and Mourougane (2014) for OECD countries whereby inefficiency is assumed to vary over time. This simplifying assumption was judged preferable for Asian economies for which data quality and availability is somewhat limited.

\section{Estimation method}

Equation (4) is estimated using Stochastic Frontier Analysis SFA over the period 1999-2008 (Murty and Kumar, 2002, Färe et al. 2004, Cuesta et al., 2009). A range of models have been examined, using $\mathrm{CO}_{2}, \mathrm{SO}_{2}$, NOx and PM10 pollutants. In theory, pollutants could have been progressively combined in the translog function to finally derive a model that includes all of them. However, there is evidence that the various pollutants, which are mainly produced during the combustion process, are highly correlated (Table 1). Incorporating all of them in a single production function would lead to unstable results. A simpler alternative, whereby pollutants are considered individually, was thus considered more suitable. Estimates account for the heterogeneity across countries and over time to capture the effect of specific events or peculiarities (e.g. size of the informal sector).

Table 1. Correlations across pollutants

\begin{tabular}{ccccc}
\hline & $\mathrm{CO}_{2}$ & $\mathrm{NOx}$ & $\mathrm{SO}_{2}$ & $\mathrm{PM}_{10}$ \\
\hline $\mathrm{CO}_{2}$ & 1.00 & & & \\
$\mathrm{NOx}$ & $0.99^{\star}$ & 1.00 & & \\
$\mathrm{SO}_{2}$ & $0.99^{\star}$ & $0.99^{\star}$ & 1.00 & \\
$\mathrm{PM}_{10}$ & $0.85^{*}$ & $0.91^{\star}$ & $0.87^{\star}$ & 1.00 \\
\hline
\end{tabular}

Note: A star means the correlation is significant at $1 \%$.

Source: Authors' calculations.

One of the main difficulties of the approach is to estimate e (y,wr), the elasticity of emissions to output. This requires not only to estimate the parameters from equation (4) but also to quantify the logs of inputs and undesirable outputs variables, which are coming from the derivatives of the translog's cross-terms. Observed input and undesirable output data that vary across time and countries cannot be used as proxies as these terms should be derived from the most efficient production and for country-specific production scale. The computation also has to cope with measurement errors, which are likely to be significant here as the analysis focused on a group of emerging and developing economies, whose data reliability can sometimes be questioned. In fine, using observed data could lead to implausible volatility in the elasticity and in turn the shadow prices.

Against this background, the elasticity has been computed at the mean value of the sample (see Aiken and Pasurka (2003) for a similar approach). While in principle, this elasticity can vary along the frontier of efficiency and decline in line with higher production scales, computing an average across countries is a way to proxy the elasticity that would apply to a representative country.

Data

Data on pollution are coming from different sources. Total $\mathrm{CO}_{2}$ emissions from fuel combustion were calculated by the International Energy Agency. $\mathrm{NOx}, \mathrm{SO}_{2}$ and $\mathrm{PM}_{10}$ emissions are from the Emission Database for Global Atmospheric Research (EDGAR). They are estimated using a model from the National Institute for Public Health and the Environment, the Netherlands (RIVM) and are expressed in thousand tons. All data have been downloaded from the EDGAR (v.4.2) and are available for all the countries for the period 1970-2008. 
The best option to capture natural resource extraction currently available to our knowledge is to use the World Bank's wealth dataset which provides information over the period 1990 to 2008. The database is fully documented in World Bank (2011). It covers important sub-soil assets, including oil, gas, bauxite, copper, lead, nickel, phosphate, tin, zinc, gold, silver, iron ore, soft and hard coal and timber. The absence of a complete set of volume and price data on water, land and renewable resources such as fish stocks, preclude their inclusion in the analysis despite their importance for ASEAN economies.

Although data are available since the beginning of the 1990s for most countries, the sample has been restricted to the post-Asian crisis period given the structural break the later caused in the Asian countries.

\section{Shadow price estimates}

Full estimation results can be found in Annex 1. Output elasticities for capital and natural resources are stable across all the models and of reasonable order of magnitude. Labour output elasticity varies somewhat across estimates and in particular loses significance in the $\mathrm{SO}_{2}$-based model. It remains nonetheless of plausible magnitude in all cases.

Desirable output is statistically and significantly associated with the emission of pollutants (Table 2). Estimates of $\mathrm{CO}_{2}$ output elasticities are found to be close to 0.2 , higher than those found for other pollutants. $\mathrm{SO}_{2}$ elasticity appears to be about half the value of $\mathrm{CO}_{2}$ elasticity. Both $\mathrm{NOx}$ and $\mathrm{PM}_{10}$ elasticities are small, but correctly-signed and significant.

Elasticities reported in Table 2 are used to derive shadow prices, using formula (2). As expected all pollutant elasticities are negatively signed and significant. As a result shadow prices are also negative in all countries, but their amplitude varies markedly across countries and pollutants (Table 3). 
Table 2. Elasticity estimates to output growth

\begin{tabular}{|c|c|c|c|c|c|c|c|}
\hline Elasticity & Capital & Labour & $\begin{array}{l}\text { Natural } \\
\text { resource }\end{array}$ & $\mathrm{CO}_{2}$ & $\mathrm{SO}_{2}$ & $\mathrm{NO}_{x}$ & PM10 \\
\hline MODEL $\mathrm{CO}_{2}$ & 0.45 & 0.50 & 0.12 & 0.17 & & & \\
\hline$p$-value & 0.00 & 0.00 & 0.01 & 0.00 & & & \\
\hline MODEL SO & 0.58 & 0.21 & 0.14 & & 0.09 & & \\
\hline$p$-value & 0.00 & 0.21 & 0.00 & & 0.00 & & \\
\hline MODEL NOX & 0.58 & 0.49 & 0.14 & & & 0.04 & \\
\hline$p$-value & 0.00 & 0.01 & 0.00 & & & 0.01 & \\
\hline MODEL $\mathrm{PM}_{10}$ & 0.56 & 0.59 & 0.16 & & & & 0.03 \\
\hline$p$-value & 0.00 & 0.00 & 0.00 & & & & 0.03 \\
\hline
\end{tabular}

Note: Output elasticities are derived from a linear combination of the frontier parameters, using the estimated coefficients of the translog function and mean values. The figures are shown with positive values for convenience, but estimates from equation (4) are all negatively signed. A p-value exceeding 0.05 indicates that the elasticity is not significant at $5 \%$.

Source: Authors' calculations.

For each gas, shadow prices are expressed in 2000 PPP USD per ton of that gas ('USD per ton' in what follows). Differences in shadow prices across the various pollutants reflect this difference in units, and more importantly differences in the price of GDP and in the intensity ratio. More specifically, the intensity ratio which is about 100 to 1000 times higher for $\mathrm{SO}_{2}$, NOx and PM10 than for $\mathrm{CO}_{2}$, explains a large part of the difference between the shadow price for $\mathrm{CO}_{2}$ and those of the other pollutants.

$\mathrm{CO}_{2}$ shadow prices in most countries are around -200/-500 USD per ton. The highest $\mathrm{CO}_{2}$ shadow prices (in absolute values) are found for Cambodia, Lao PDR and the Philippines and are respectively about six and three times higher than those in China. This finding is consistent with efficiency scores derived from the SFA model, which suggest that these countries operate at or close to the frontier of efficiency. It should be noted, however, that in this framework technology is measured at the aggregate national level, masking sectoral or firm differences in production process. Specifically, less industrialised economies are likely to produce smaller quantities of pollutant per unit of GDP compared to more industrialised ones. As such, results should not be solely interpreted in terms of country technical efficiency.

There is little guidance in the recent literature on $\mathrm{CO}_{2}$ shadow prices in Asian economies. Estimates from existing studies (mostly on developed economies) vary widely, ranging for instance from an extremely low -478 USD per ton to a very high level of -0.01 in some countries (Maradan and Vassiliev, 2005; Salnikov and Zelenyuk, 2005). Although shadow prices estimates obtained for Asian economies in this work appear to be on the low side, their order of magnitude remains plausible. 
Table 3. Shadow prices and ratio of output over emissions

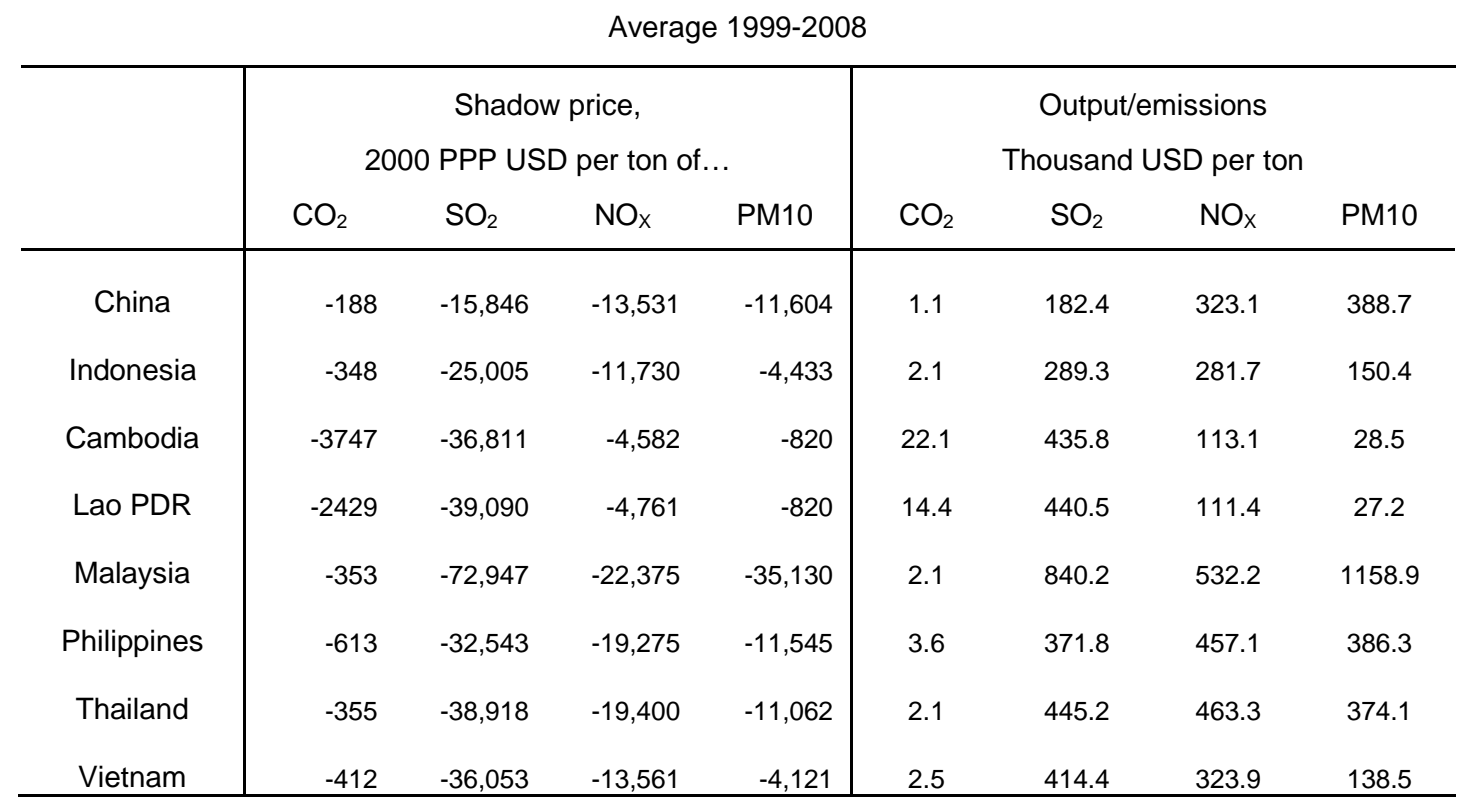

Source: Authors' calculations.

Developments in $\mathrm{CO}_{2}$ shadow prices over the 1999-2008 period suggest that ASEAN countries and China have strengthened their regulatory framework and encouraged the adoption of clean technologies since the Asian crisis (Figure 5). Lao PDR, the Philippines and Indonesia experienced the sharpest decrease, especially since 2005, pointing to deeper efforts to adopt cleaner but also increasingly more efficient technologies than in peer countries.

The amplitude of shadow prices for $\mathrm{SO}_{2}$ is estimated to vary widely across countries, the highest price (in absolute terms) being observed in Malaysia and the lowest in China. Most countries experienced a downward trend since 1999, with the decline being particularly marked in Lao PDR since 2005. Cambodia stands out as an exception and experiences a gradual but steady increase in its $\mathrm{SO}_{2}$ shadow prices.

Unfortunately, these results cannot be easily compared with existing estimates from the literature, which suggests results are very much dependent on the time, sectoral and geographical scope of the study and the approach (Färe et al., 2005; Coggins and Swinton, 1996, Mekaroonreung and Johnson, 2012; Lee et al., 2002). Shadow prices for $\mathrm{SO}_{2} / \mathrm{SOx}$ in the United States are found to vary from -18.1 USD per ton (Keilbach, 1995) to almost -6000 (Swinton, 1998). Estimates for the Korean electric power sector for the period 1990-95 would be higher, reaching -3107 USD per ton (Lee et al., 2002). 
USD per ton of $\mathrm{CO}_{2}$

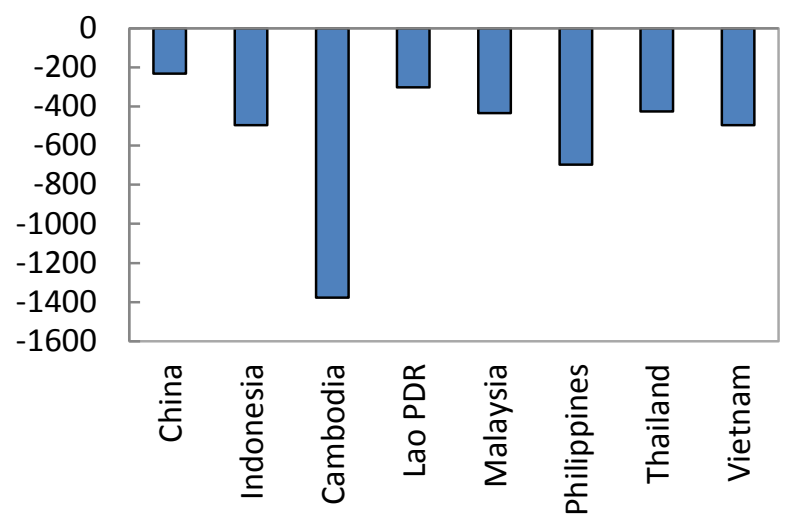

USD per ton of $\mathrm{NO}_{\mathrm{x}}$

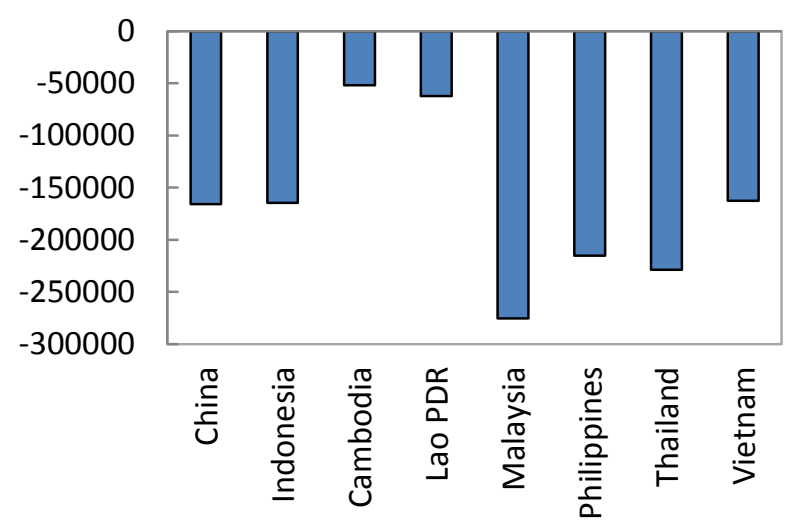

USD per ton of $\mathrm{SO}_{2}$

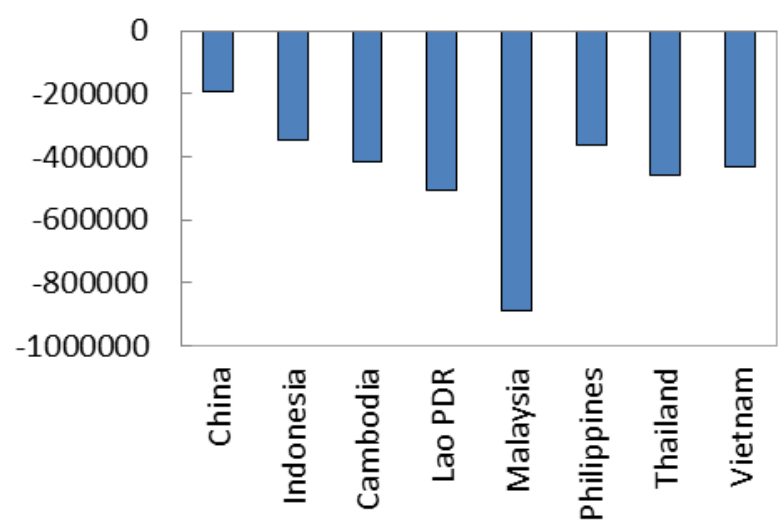

USD per ton of PM10

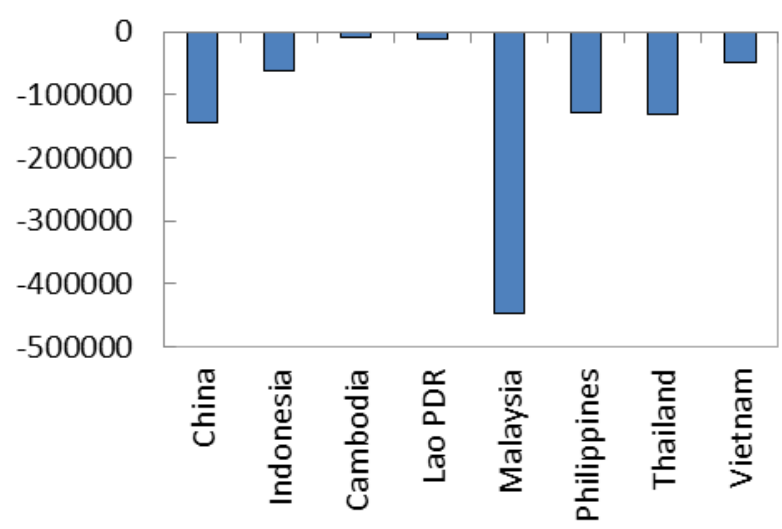

Source: Authors' calculations.

$\mathrm{Hu}$ et al. (2006) is probably is the study that is the most comparable to the work presented here, as the authors use an output distance function to compute shadow prices of $\mathrm{SO}_{2}$ emissions in Chinese provinces during the period 1996-2002. They also found that on average shadow prices tend to become more and more negative over the year but the profile varies widely from one province to another.

Shadow prices estimates for $\mathrm{NOx}$ and $\mathrm{PM}_{10}$ display a very large variability across countries. The highest prices (in absolute terms) are found in Malaysia and the smallest in Lao PDR. The disproportional high intensity of NOx and PM10 emissions per unit of GDP in the latter country explains such negative shadow prices. Across countries, estimates of NOx shadow prices are much higher (in absolute terms) than those found in Lee et al. (2002), reflecting the difference in scope and methodology. Over time the largest declines in $\mathrm{NO}_{\mathrm{x}}$ and $\mathrm{PM}_{10}$ shadow prices are observed in Lao PDR. 
Figure 6. Evolution of shadow prices of pollutants.

Difference 1999-2008, Index 1 in 2000

$\mathrm{CO}_{2}$

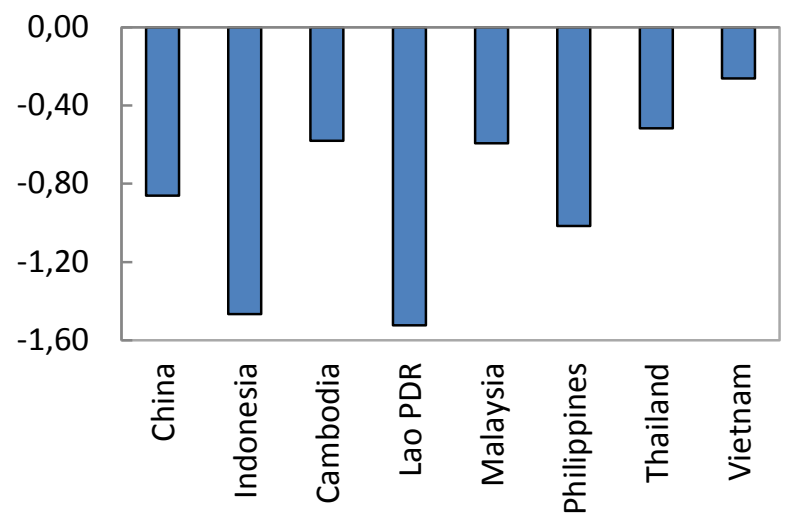

NOx

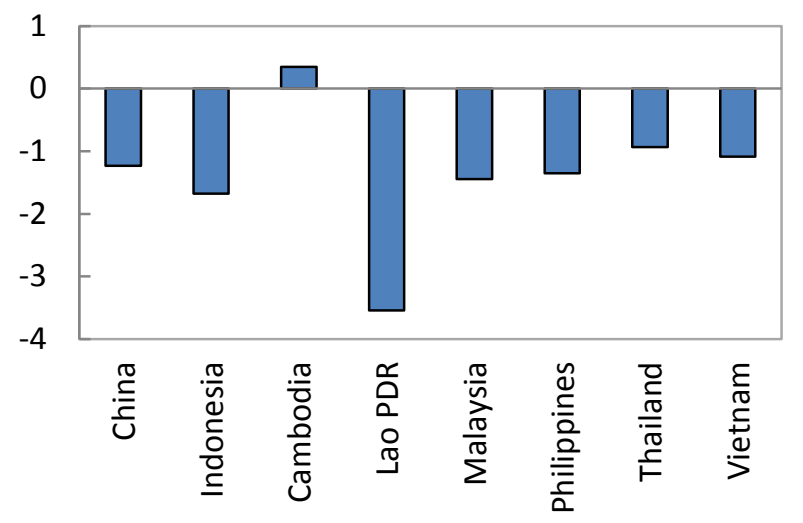

$\mathrm{SO}_{2}$

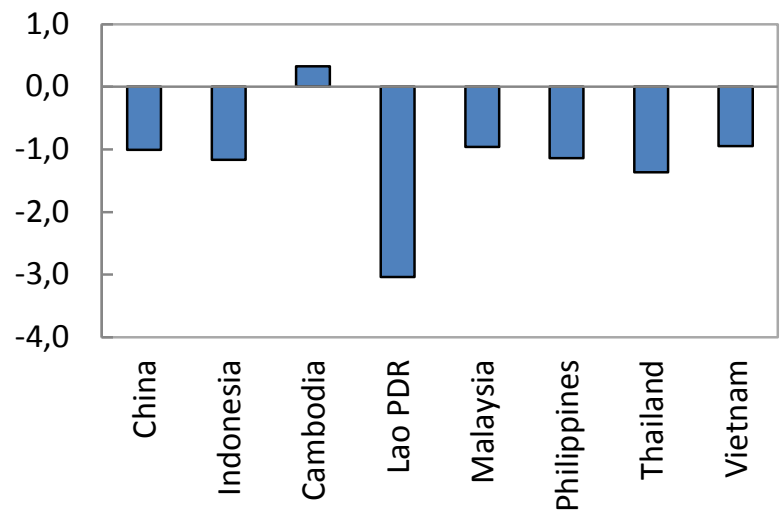

$\mathrm{PM}_{10}$

Source: Authors' calculations.

\subsection{Estimates of MFP adjustment for pollutants}

Shadow prices computed in the preceding section are used to correct MFP growth for the effect of pollution using equation (1).

$$
m f p_{a d j \_p l}=m f p-\frac{p_{W} W}{p_{Q Q}}(y-w)
$$

Where $\mathrm{mfp}_{\text {adj_pol }}$ is the growth rate of MFP adjusted for the pollution, $\mathrm{p}_{\mathrm{w}}$ is the shadow price of pollution, $\mathrm{W}$ the quantity of pollutants, $\mathrm{P}_{\mathrm{Q}}$ the price of effective output, $\mathrm{Q}$ effective output, $\mathrm{y}$ the growth rate of the desirable output and $\mathrm{w}$ the growth rate of the quantity of pollution emitted during the production process.

$\mathrm{mfp}_{\text {adj_pol }}$ growth will be higher than standard $\mathrm{mfp}$ growth when output grows faster than pollution emissions, as shadow prices are negative. The amplitude of the adjustment is scaled by the weight of undesirable output in effective output. 
The adjustment for pollution of standard measures of MFP growth appears to be sizeable, though it should be relativised given the margin of errors surrounding such measures. It should be also noted that the adjustment made here is limited to costs for producers only and is by no means representative of what would be the cost for the society as a whole. In addition, only a few pollutants have been tested, given the limited data availability in this area.

Accounting for pollution leads to very different adjustments to standard MFP growth measures across countries (Table 4). Pollution-corrected MFP growth is markedly higher than the standard measure in Lao PDR and the Philippines. $\mathrm{CO}_{2}$ and $\mathrm{SO}_{2}$ account for most of the adjustment in the Philippines, while all air pollutants contribute significantly to the adjustment in Lao PDR. In the latter country, $\mathrm{SO}_{2}, \mathrm{NOx}$ and $\mathrm{PM}_{10}$ experienced double-digit negative growth rates during the 2000s.

Table 4. MFP growth adjustment for pollution

Percentage point, average 1999-2008

\begin{tabular}{l|c|cccc}
\hline & $\begin{array}{c}\text { MFP } \\
\text { adjustment }\end{array}$ & $\begin{array}{c}\text { of which: } \\
\mathrm{CO}_{2}\end{array}$ & $\mathrm{SO}_{2}$ & $\mathrm{NOx}$ & $\mathrm{PM}_{10}$ \\
\hline China & 1.2 & 0.4 & 0.3 & 0.2 & 0.3 \\
Indonesia & 1.1 & 0.5 & 0.1 & 0.2 & 0.3 \\
Cambodia & -1.2 & 0.9 & -1.1 & -0.6 & -0.4 \\
Lao PDR & 6.8 & 0.7 & 3.1 & 1.8 & 1.2 \\
Malaysia & 0.7 & -0.3 & 0.2 & 0.3 & 0.4 \\
Philippines & 2.5 & 1.0 & 0.7 & 0.4 & 0.4 \\
Thailand & 1.2 & 0.1 & 0.8 & 0.2 & 0.1 \\
Vietnam & 0.0 & -0.7 & 0.3 & 0.2 & 0.3 \\
\hline
\end{tabular}

Source: Authors' calculations.

The size of the adjustment to MFP growth is found be much lower in China, Indonesia and Thailand to around 1 percentage point, as real GDP growth outpaced pollutants emissions growth in these countries. The adjustment is estimated to be slightly lower (around 0.7 percentage point) for Malaysia, as $\mathrm{CO}_{2}$ emissions have grown at a slower pace than GDP and have compensated somewhat the effect of rapid growth in $\mathrm{NOx}, \mathrm{SO}_{2}$ and $\mathrm{PM}_{10}$ emissions.

By contrast, emissions have grown faster than activity in Cambodia, leading to a negative adjustment of standard MFP growth. The adjustment would be nil in Vietnam. While emissions of $\mathrm{SO}_{2}$, NOx and PM10 would have led to a positive adjustment to standard MFP growth, their effect is estimated to be fully compensated by $\mathrm{CO}_{2}$ emission growth, which outpaced GDP growth. 


\section{CONCLUSION}

This paper seeks to correct traditional measures of MFP growth for the effect of pollution in a group of emerging and developing ASEAN economies and China. For that purpose, it first constructs new measures of MFP growth for these countries and applies the growth accounting framework developed by Brandt et al. (2014) to adjust these measures using time-varying country-specific shadow prices for pollutants.

Shadow prices for pollutants are found to vary widely across the economies, depending on national environmental regulations, the use of inefficient abatement technologies, and the structure of the economy. In all countries but Cambodia, shadow prices of the various pollutants have experienced a downward trend since 1999, suggesting that ASEAN countries and China have strengthened their regulatory framework and encouraged the adoption of clean technologies since the Asian crisis. Such a trend can also be observed in Cambodia but only for the shadow price of $\mathrm{CO}_{2}$.

The empirical work suggests that adjusting for the effect of pollution could significantly alter standard MFP growth in most Asian countries. Such correction would lead to an increase above 2 percentage points in Lao PDR and the Philippines, of about 1 in China, Indonesia, Thailand and in Malaysia. It would be negative in Cambodia and nil in Vietnam.

The analysis is subject to a number of caveats. First, the estimation results rely on the use of data whose quality can in some cases be questioned. Second, the empirical work has been undertaken at a very aggregate level and can hide wide disparity across sectors. In this regard, undertaking a similar exercise at the sectoral or firm level is likely to be very informative. Finally the estimation method could be refined to better account for country heterogeneity. One extension of the work could be to better capture the output-undesirable output elasticity, and try other proxies than the average sample used in this paper. Ideally, it would be better to estimate country-specific elasticity but this may require changing the framework to be able to test the significance of those elasticities. More importantly, measuring large uncertainties surrounding shadow price estimates, for instance through Monte-Carlo simulations, would be very useful both from an academic and a policy perspective. 


\section{REFERENCES}

Aiken D.V. and C. Pasurka Jr (2003), “Adjusting the Measurement of US Manufacturing Productivity for Air Pollution Emissions Control”, Resource and Energy Economics 25, 329-351.

Beffy P.O., P. Ollivaud, P. Richardson and F. Sédillot (2006), "New OECD Methods for Supply-Side and Medium-Term Assessments: A Capital Services Approach", OECD Economics Department Working Paper 482.

Brandt N., P. Schreyer and V. Zipperer (2014), ' Productivity Measurement with Natural Capital and Bad Output', OECD Economics Department Working Paper No. 1154, OECD Publishing, Paris.

Clean Air Alliance of China (2013), $12^{\text {th }}$ Five-Year Plan on Air Pollution Prevention and Control in Key Regions, China Clean Air Policy Briefing No.1, April.

Cuesta R. A, C.A. Knox Lovell, J.L. Zofio (2009), "Environmental Efficiency Measurement with Translog Distance Functions: A parametric Approach”, Ecological Economics 68, 2232-2242.

Dang, T and A. Mourougane (2014), "Estimating Shadow Prices of Pollution in OECD Economies", OECD Green Growth Papers, No. 2014-02, OECD Publishing, Paris.

Färe R, S. Grosskopf, D. Margaritis (2010), "Directional Distance Functions and Applied Economics, A Tribute to R.G. Chambers", mimeo.

Färe R, S. Grosskopf, D. Noh and W. Weber (2005), "Characteristics of a Polluting Technology: Theory and Practice", Journal of Econometrics, Vol. 126, 469-492.

Färe R, S. Grosskopf, C.A. Knox Lovell and S. Yaisawarng (1993), "Derivation of Shadow Prices for Undesirable Outputs: A Distance Function Approach", The Review of Economics and Statistics, Vol. 75(2), 374-380.

Färe R., S. Grosskopf, C. A. K. Lovell and C. Pasurka (1989), "Multilateral Productivity Comparisons when some Ouputs are Undesirable: A non Parametric Approach", The Review of Economics and Statistics, Vol. 71, No. 1, 90-98.

Hu J.L. (2006), "Efficient Air pollution Abatements of Regions in China", International Journal of Sustainable Development and World Ecology, 13:4, 327-340. Beijin.

Hu J.L., Y.H. Chiu and T-Y. Ke (2006), "Shadow Prices of SO2 Abatements for Regions in China",

Keilbach, M. (1995), "Estimation of the Value of the Marginal Product of Emissions in a Country where Emissions Output is Regulated - An Empirical Study", Environmental and Resource Economics, Vol. 5, 305319. 
Kumar S. and D. N. Rao (2002), "Estimating Marginal Abatement Cost of SPM: An Application to the Thermal Power Sector in India", Energy Studies Review, 11, 76-92.

Lee, J.D., J.B. Par T.Y. Kim (2002), "Estimation of the Shadow Prices of Pollutants with Production/Environment Inefficiency Taken into account: a Nonparametric Directional Distance Function Approach”, Journal of Environmental Management, Vol. 64, Issue 4, 365-375.

Maradan D. and A. Vassiliev (2005), "Marginal Costs of Carbon Dioxide Abatement: Empirical Evidence from Cross-Country Analysis", Schweizerische Zeitschrift für Volkswirtschaft une Statistik, Vol. 34, 723-32.

Mekarooneung M. and A. Johnson (2012), "Estimating the Shadow Prices of $\mathrm{SO}_{2}$ and NOx for U.S. Coal Power Plants: A Convex Non Parametric Least Squares Approach", Energy Economics, Vol. 34, Issue 3, 723732.

Murty, M.N and S. Kumar (2002), "Measuring Cost of Environmentally Sustainable Industrial Development in India: A Distant Function Approach", Environment and Developments Economics, Vol. 7, Issue 3 .

OECD (2014), “The Cost of Air Pollution: Health impacts of road transport", OECD Publishing, Paris.

Qi S., L. Xu and J. Coggins (2004), "Deriving Shadow Prices of Environmental Externalities", University of Minesota.

Salnykov M. and V. Zelenyuk (2005), "Estimation of Environmental Efficiencies of Economies and Shadow Prices of Pollutants in Countries in Transition," EERC Working Paper Series 05-06e, EERC Research Network, Russia and CIS.

Schreyer P. (2010), "Measuring Multi-factor Productivity when Rates of Return Are Exogenous", Chapter 2, pp. 13-40 in W.E. Diewert, B.M. Balk, D. Fixler, K.J. Fox and A.O. Nakamura (2010), Price and Productivity Measurement, Volume 6, Trafford Press.

Sheng Y. (2012), "The Challenges of Promoting Productive, Inclusive and Sustainable Urbanization", in Urbanization in Southeast Asia Issues and Impact, edited by Y. Sheng and M. Thuzar, Institute of Southeast Asian Studies, Singapore.

Shephard, R. W. (1970), Theory of Cost and Production Functions, Princeton University Press.

Solow R. (1957), "Technical Change and the Aggregate Production Function", The Review of Economics and Statistics, Vol. 39, No. 3 (Aug., 1957), 312-320

Swinton J.R. (1998), “At What Cost Do We Reduce Pollution? Shadow Prices of $\mathrm{SO}_{2}$ emissions”, Energy Journal, 4, 63-83.

Park J. (2010), "Projection of Long-Term Total Factor Productivity Growth for 12 Asian Economies", ADB Economic Working Paper Series No. 227, Manila.

World Bank (2011), "The Changing Wealth of Nations: Measuring Sustainable Development in the New Millennium", The World Bank, Washington, USA.

Zhang, T. and E. Garvey (2008), "A Comparative Analysis of Multi-Output Frontier Models", Journal of Zhejiang University SCIENCE A, 2008, 9(10):1426-1436 
ANNEX 1: SFA ESTIMATION RESULTS

\begin{tabular}{|c|c|c|c|c|}
\hline Variable & $\mathrm{CO}_{2}$ & NOx & $\mathrm{SO}_{2}$ & PM10 \\
\hline $\operatorname{lnCAPV}$ & $-0.4231 * * *$ & $-0.5601 * * *$ & $-0.5379 * * *$ & $0.5693 * * *$ \\
\hline $\operatorname{lnLABV}$ & $-0.5064^{* *}$ & $-0.5500^{* *}$ & $-0.3693^{*}$ & $-0.5526^{* *}$ \\
\hline InNATV & $-0.1370 * *$ & $-0.1797 * * *$ & $-0.1800 * * *$ & $0.1837 * * *$ \\
\hline $\operatorname{lnCO} 2$ & $-0.1933^{* * *}$ & & & \\
\hline lnCAPVSQ & 1.8857 & 0.6405 & 0.6184 & 0.8292 \\
\hline lnLABVSQ & -1.4128 & -2.2047 & 5.0546 & -1.1054 \\
\hline lnNATVSQ & -1.1353 & -1.2797 & $-1.6012 * *$ & $-1.4926^{*}$ \\
\hline $\operatorname{lnCO} 2 \mathrm{SQ}$ & -0.7468 & & & \\
\hline lnCAPV_lnLABV & -0.8479 & -1.8692 & -3.4212 & -2.0541 \\
\hline lnCAPV_lnNATV & -0.7306 & -0.6540 & -0.1307 & -0.8260 \\
\hline lnLABV_lnNATV & 1.5046 & 2.2842 & 1.4201 & 2.5298 \\
\hline lnCAPV_lnCO2 & -0.4897 & & & \\
\hline lnLABV_lnCO2 & 0.1654 & & & \\
\hline lnNATV_lnCO2 & 0.0426 & & & \\
\hline $\operatorname{lnNOX}$ & $-0.0355^{* *}$ & & & \\
\hline $\operatorname{lnNOXSQ}$ & $0.0952^{*}$ & & & \\
\hline lnCAPV_lnNOX & 0.1353 & & & \\
\hline lnLABV_lnNOX & -0.4366 & & & \\
\hline lnNATV_lnNOX & -0.3465 & & & \\
\hline $\operatorname{lnSO} 2$ & $-0.069 * * *$ & & & \\
\hline $\operatorname{lnSO} 2 \mathrm{SQ}$ & $0.2588 * * *$ & & & \\
\hline lnCAPV_lnSO2 & $0.6624 *$ & & & \\
\hline lnLABV_lnSO2 & $-1.9749 * *$ & & & \\
\hline lnNATV_lnSO2 & -0.5688 & & & \\
\hline $\operatorname{lnPM} 10$ & $-0.0270^{*}$ & & & \\
\hline $\operatorname{lnPM10SQ}$ & 0.0666 & & & \\
\hline lnCAPV_lnPM10 & -0.2056 & & & \\
\hline $\operatorname{lnLABV} \operatorname{lnPM} 10$ & 0.6600 & & & \\
\hline lnNATV_lnPM10 & -0.1070 & & & \\
\hline constant & $0.0896^{* * *}$ & $0.0995^{* * *}$ & $0.1104^{* * *}$ & $0.0943^{* * *}$ \\
\hline \multicolumn{5}{|l|}{ Statistics } \\
\hline Observations & 87 & 87 & 87 & 87 \\
\hline Log-likelihood & 194.41 & 190.93 & 204.53 & 190.74 \\
\hline Chi2 & 4324.50 & 3934.65 & 5404.41 & 3903.96 \\
\hline AIC & -318.82 & -311.86 & -339.06 & -311.47 \\
\hline
\end{tabular}

legend: ${ }^{*} \mathrm{p}<0.05 ;{ }^{* *} \mathrm{p}<0.01 ;{ }^{* * *} \mathrm{p}<0.001$

Times and country dummy have been introduced in the estimation 
www.oecd.org/greengrowth 